for Biological Invasions

\title{
Global compositional variation among native and non-native regional insect assemblages emphasizes the importance of pathways
}

Andrew M. Liebhold, Takehiko Yamanaka, Alain Roques, Sylvie Augustin, Steven L. Chown, Eckehard G. Brockerhoff, Petr Pyšek

\begin{abstract}
A.M. Liebhold, US Forest Service Northern Research Station, 180 Canfield St., Morgantown, WV 26505 USA, email: aliebhold@fs.fed.us

T. Yamanaka, Natural Resources Inventory Center, National Institute for AgroEnvironmental Sciences, Kannon-dai 3-1-3, Tsukuba-city, Ibaraki, Japan, email: apple@affrc.go.jp
\end{abstract}

A. Roques, INRA UR0633, Zoologie Forestière, Ardon, CS 40001, 45075 Orléans Cedex, France, email: alain.roques@orleans.inra.fr

S. Augustin, INRA UR0633, Zoologie Forestière, Ardon, CS 40001, 45075 Orléans Cedex, France, email: sylvie.augustin@orleans.inra.fr

S.L. Chown, School of Biological Sciences, Monash University, Victoria 3800, Australia, email: steven.chown@monash.edu

E.G. Brockerhoff, Scion (New Zealand Forest Research Institute), P.O. Box 29237, Christchurch 8540, New Zealand email: Eckehard.Brockerhoff@scionresearch.com

P. Pyšek, Institute of Botany, The Czech Academy of Sciences, CZ 25243 Průhonice, Czech Republic, \& Department of Ecology, Faculty of Science, Charles University in Prague, Viničná 7, CZ 12844 Prague 2, Czech Republic \& Centre for Invasion Biology, Department of Botany \& Zoology, Stellenbosch University, Matieland 7602, South Africa e-mail: pysek@ibot.cas.cz 
1 Abstract Insects are among the world's most ecologically and economically important

2 invasive species. Here we assemble inventories of native and non-native species from 20

3 world regions and contrast relative numbers among these species assemblages.

4 Multivariate ordination indicates that the distribution of species among insect orders is

5 completely different between native and non-native assemblages. Some orders, such as the

6 Psocoptera, Dictyoptera, Siphonaptera, Thysanoptera, and Hemiptera, are always over-

7 represented in the non-native compared to native assemblages. Other orders, such as the

8 Plecoptera, Trichoptera, Ephemeroptera, Odonata, Mecoptera and Microcoryphila, are

9 consistently under-represented in non-native assemblages. These patterns most likely

10 arise both as a result of variation among taxa in their association with invasion pathways

11 responsible for transporting species among world regions, as well as variation in life-

12 history traits that affect establishment potential. However, our results indicate that species

13 compositions associated with invasiveness are fundamentally different from compositions

14 related to insularity, indicating that colonization of islands selects for a different group of

15 insect taxa than does selection for successful invaders. Native and non-native assemblage

16 compositions were also related, to a lesser extent, to latitude of the region sampled.

17 Together, these results illustrate the dominant role of invasion pathways in shaping the

18 composition of non-native insect assemblages. They also emphasize the difference between

19 natural background colonization of islands and anthropogenic colonization events, and

20 imply that biological invasions are not a simple subset of a long-standing ecological

21 process. 
1 Keywords biological invasion, establishment, fauna, island, introduction pathway, insect

2 order, multivariate analysis 
Introduction

3

4 Insects are the most diverse class in the animal kingdom, and similarly non-native insect

5 species outnumber all other invading animal species. The Insecta also includes some of the

6 most notorious damaging invaders. Species such as the Argentine ant, Linepithema humile,

7 the Colorado potato beetle, Leptinotarsa decemlineata, the Asian tiger mosquito, Stegomyia

8 albopicta, and the emerald ash borer, Agrilus planipennis are infamous for their ecological

9 and economic impacts (Kenis et al. 2009; Kettunen et al. 2009; Herms and McCullough

10 2014). As a group, insects are also widely known for their extensive life-history and

11 ecological diversity. Insects have evolved to exploit nearly every major biome, with the

12 exception of most marine areas (but see Cheng 1976), and play a diversity of ecological

13 roles such as herbivores, predators and detritivores.

15 Considering the tremendous variation in insect ecology and life history, it would be

16 useful to understand which types of insects are the most common invaders. This is an

17 important question given the need to improve forecasting of future invasions and identify

18 which invading species are likely to have ecological and/or economic impacts (Ricciardi et

19 al. 2013; Simberloff et al. 2013). Improved forecasting will enable impacts to be more

20 efficiently managed by targeting prevention and surveillance efforts (Hulme et al. 2008;

21 Lee and Chown 2009; Blackburn et al. 2014). 
The frequency with which different groups of insects has invaded can be expected to

2 reflect both their invasiveness and their tendencies to become associated with invasion

3 pathways. The invasiveness of a species reflects the extent to which a species' life history

4 traits predispose it to successfully invade (Richardson and Pyšek 2006). For example, a

5 species that is highly specific to a single host organism may be unlikely to invade if that

6 host is not present, while a more polyphagous species might have greater success as an

7 invader (Hazell et al. 2008). Other characteristics, such as body size, have been found to be

8 associated with invasion success (Lawton et al. 1986; Gaston et al. 2001).

10 What characteristics might set effective colonists apart from those that are less

11 successful has been a long-standing topic in ecology and biogeography. Concepts such as

12 the taxon cycle, which emphasize ecological and evolutionary interactions between

13 colonizing and resident species (Ricklefs and Bermingham 2002), and disharmony, which

14 goes to the heart of the characteristics of successful long-distance colonizers (Carlquist

15 1965), reflect this interest in the colonization process. Work in this area has surged given

16 the need to understand and forecast the characteristics of successful invaders and the

17 environments that might be most receptive to new invaders (Puth and Post 2005;

18 Richardson and Pyšek 2006; Blackburn et al. 2011; Pyšek et al. 2012). In particular, much

19 focus has been given to the extent to which various traits and the extent of their plasticity

20 might be useful to forecast and to understand differential success in crossing various

21 barriers to invasion and in subsequently having an impact (e.g., Daehler 2003; Chown et al.

22 2007, 2012; van Kleunen et al. 2010; Jarošík et al. 2015). 
The probability that a species may invade a new region is also strongly affected by

2 the extent to which it may become linked to invasion pathways. Many global insect

3 invasion pathways have been identified and these include trade in agricultural products,

4 movement of plant parts by international travelers, shipments of stored grain, trade in

5 living plants, hitchhiking (e.g. on the outside of shipping containers) and wood packing

6 material (Kiritani and Yamamura 2003; Brockerhoff et al. 2006; Liebhold et al. 2006, 2012).

$7 \quad$ Individual insect species vary considerably in the extent to which they are transported by

8 these various pathways and this profoundly influences the likelihood that they may invade

9 a new region (Kiritani and Yamamura 2003; Brockerhoff et al. 2014; Yamanaka et al. 2015).

11 Here we compile data on the composition of insect assemblages from several

12 different parts of the world and characterize these assemblages based upon the numbers of

13 species in each insect order. We then use these data to address, for the first time in the

14 literature, the following questions: 1) Do the compositions of non-native insect

15 assemblages differ consistently from native assemblages? 2) Are there certain insect orders

16 that are consistently over-represented and others that are under-represented in non-native

17 assemblages compared to native assemblages? 3) Is the composition of native insect

18 assemblages on islands more similar to non-native assemblages than are assemblages in

19 mainland areas?

21 Methods 
1 Numbers of insect species in each order were derived from a series of species inventories

2 obtained from 20 regions from a variety of sources (Table 1). These data consisted of

3 species frequencies for each order in both native and non-native assemblages in the

4 following continental regions: Europe, France, Italy, North America, Portugal, and Spain.

5 The same data were obtained for 12 islands: the Canary Islands, Corsica, Great Britain, the

6 Hawaiian Islands, Japan (excluding Ogasawara and Okinawa Islands), Ogasawara Islands,

7 Okinawa Islands, Madeira, Malta, New Zealand (excluding the Kermadec, Chatham and sub-

8 Antarctic islands), Sardinia, Sicily. Data for Europe included the same species from Great

9 Britain, Corsica, France, Italy, Madeira, Malta, Portugal, Sardinia, Sicily and Spain. Data on

10 native and non-native species for North America were limited to species established in the

11 USA and Canada (not including Mexico or Hawaiian Islands). We also compiled counts by

12 order for native and non-native insect species from 25 southern ocean islands described in

13 Chown et al. (1998), and subsequently updated (Chown and Convey, 2015). These islands

14 are generally small (areas ranging 1-7200 $\mathrm{km}^{2}$ ) and most are sub-Antarctic (latitudes

15 ranging $37.1^{\circ}-54.6^{\circ} \mathrm{S}$ ). Rather than consider each southern island as replicate regions, we

16 pooled data from all 25 islands to generate the number of species by order across all

17 islands. We also assembled comparable data for the non-native assemblage in the

18 Galápagos Islands and all world native insect species. In compiling these data, species were

19 included regardless of whether introductions were considered accidental or intentional

20 (e.g., biological control agents).

22 In comparing numbers of species in each insect order among assemblages, we

23 limited analyses to the 20 most common (in terms of total numbers in the world) orders: 
1 Coleoptera, Hymenoptera, Diptera, Lepidoptera, Hemiptera, Orthoptera, Trichoptera,

2 Dictyoptera, Thysanoptera, Odonata, Psocoptera, Ephemeroptera, Plecoptera,

3 Phasmatodea, Dermaptera, Strepsiptera, Microcoryphia, Mecoptera, Zygentoma,

4 Embioptera.

5

Nonmetric Multidimensional Scaling (NMDS) was employed to characterize

7 differences among all (both native and non-native) assemblages based upon the

8 distribution of species among orders (Kenkel and Orlóci 1986). The fraction of all species in

9 each assemblage falling in a given insect order was first square-root transformed to

10 stabilize the scale effect. Following multidimensional scaling, each assemblage was plotted

11 using their scores for the first two NMDS axes; the position of each assemblage in this space

12 provided a map of taxonomic similarities and differences among assemblages. We also

13 plotted the position of each order which was calculated as the centroid of all assemblages.

14 The NMDS ordination was based upon Bray-Curtis dissimilarity distances and computed

15 using the R-library vegan in the statistical software R (Version 2.14.0, http://www.r-

16 project.org). In order to more fully understand the drivers of assemblage structure, we

17 considered the role of latitude, calculated as the centroid of each region. We used the

18 ordisurf function (within the vegan library) to contour latitude in the space defined by the

19 first two NMDS axes; ordsurf fits smooth surfaces across ordination spaces using thinplate

20 splines with cross-validatory selection of smoothness.

22 Data from the southern islands lacked counts for Siphonaptera and this order was

23 excluded from the analysis above. Counts for numbers of Siphonaptera were available from 
1 the other 19 regions so we performed an identical ordination using counts for these 19

2 regions (southern islands excluded) for the 20 insect orders plus numbers of Siphonaptera.

$4 \quad$ For each region, we plotted numbers of native species vs. numbers of non-native

5 species by insect order. On the same graph we plotted the line of expected numbers of

6 species under the assumption that in the non-native assemblage, the proportion

7 represented per order was the same as in the native assemblage. We also plotted the $95 \%$

8 prediction interval for this assumption based on the bionomial distribution ( $p=$ non-native

9 / native numbers of species). Orders were considered under- or over-represented in the

10 non-native assemblage when they fell outside of the 95\% prediction interval. For each

11 order in each region, we also computed the difference between the expected and observed

12 numbers and plotted the distribution of these differences.

13

\section{Results}

15

16 Ordination using NMDS indicated that the taxonomic distribution of non-native species was

17 completely distinct from that of native assemblages (Figure 1a); scores on the first NMDS1

18 axis for natives were consistently greater than those for non-natives and there was no

19 overlap. For both native and non-native assemblages, there did not appear to be any

20 consistent difference between island (e.g., Okinawa, Hawaii) and mainland (e.g., Europe,

21 North America) regions with respect to the first NMDS axis. 
Loadings on NMDS1 were very low for Psocoptera, Dictyoptera, Thysanoptera and

2 Hemiptera and very high for the aquatic orders, Plecoptera, Trichoptera, Ephemeroptera

3 and Odonata as well as for the largely terrestrial orders Mecoptera and Microcoryphila

4 (Fig. 1b). Given that the first NMDS axis represents the difference between native and non-

5 native assemblages, this implies that large relatively numbers of Psocoptera, Dictyoptera,

6 Siphonaptera, Thysanoptera and Hemiptera species are characteristic of non-native

7 assemblages and relatively large numbers of Plecoptera, Trichoptera, Ephemeroptera,

8 Odonata, Mecoptera and Microcoryphia are characteristic of native assemblages.

9 Ordination with data excluding the southern islands but including counts of Siphonaptera

10 (Figs. S1 and S2) yielded very similar patterns and the Siphonaptera fell on the far left,

11 indicating that they are particularly abundant in non-native assemblages.

13 Values of NMDS2 did not appear to differentiate native from non-native

14 assemblages. However, NMDS2 was associated with the latitude of each region, with high

15 latitude regions yielding high NMDS2 scores and more equatorial regions having low

16 scores (Fig. 1c). The association of NMDS2 with latitude was more conspicuous for native

17 assemblages (right hand portion of NMDS space: Pearson correlation coefficient (rho) =

$180.770, \mathrm{p}<.0001$ ) than that for non-native assemblages (left hand portion of NMDS space:

19 rho $=0.356, \mathrm{p}<.135)$

21 Loadings for each order on NMDS2 were very low for Orthoptera and Odonata and

22 very high for Psocoptera, Mecoptera, Ephemeroptera, Plecoptera and Trichoptera. Given

23 the association of NMDS2 with latitude (Fig. 1c), it follows that Orthoptera and Odonata 
1 species are particularly diverse in equatorial regions and Psocoptera, Mecoptera,

2 Ephemeroptera, Plecoptera and Trichoptera are particularly diverse at higher latitude

3 regions. The Mecoptera, Ephemeroptera, Plecoptera and Trichoptera were clustered in the

4 upper right corner of the NDMDS space, whereas Psocoptera were in the upper left. This

5 would suggest that the former orders are neither common in non-native assemblages nor

6 equatorial regions, whereas the Psocoptera are common in non-native communities,

7 particularly in high latitude regions.

9 While the total range of NMDS1 and NMDS2 values were comparable between

10 native and non-native assemblages, there appeared to be more clustering of points in the

11 NMDS space for native assemblages (Fig. 1a). This clustering appeared to reflect

12 geographic contagion - e.g., native faunas of continental European regions were clustered

13 together. The lack of a similar clustering within non-native assemblages suggests that these

14 alien assemblages are more unique, perhaps reflecting differences in dominant pathways.

16 Plots of numbers of native vs. non-native species in each region (Fig. 2) indicate that

17 some insect orders are proportionately more diverse in non-native assemblages than in

18 native assemblages (these fall above and outside the 95\% prediction interval). Conversely

19 other orders are of exceptionally low diversity in non-native assemblages (these fall below

20 and outside the $95 \%$ prediction interval). While the dominance of the various orders in

21 each assemblage varied considerably, there are some consistent trends. First, certain

22 orders tend to be the most diverse in almost every assemblage. As might be expected based

23 on known global species richness, the Coleoptera, Lepidoptera, Diptera, Hymenoptera and 
1 Hemiptera tend to be the dominant orders, in both native or non-native assemblages.

2 However, the Hemiptera, Psocoptera, Thysanoptera and Dictyoptera tend to be over-

3 represented in the non-native assemblages (they fall above the prediction intervals in Fig.

4 2), whereas the aquatic orders, Plecoptera, Ephemeroptera and Trichoptera tend to be

5 under-represented (they fall below the prediction intervals in Fig. 2). This is in general

6 agreement with associations seen in the NMDS1 axis (Fig. 1).

To further resolve how the relative abundance of each order varies between native

9 and non-native assemblages, we used box and whisker plots to display the differences

10 between observed numbers of species and values expected if the numbers of species were

11 proportionally the same in both the non-native and native assemblage (Fig. 3). These plots

12 indicate that the Hemiptera, Dictyoptera, Thysanoptera and Siphonaptera were

13 consistently more diverse in the non-native compared with native assemblages in the same

14 region while the opposite was true for the Diptera, Odonata, Ephemeroptera, Plecoptera

15 and Mecoptera.

\section{Discussion}

19 Predicting future invasions has long been a goal of invasion ecology (e.g., Elton 1958; Kolar

20 and Lodge 2001). Considerable work has been conducted investigating traits that are

21 associated with invasion success, though most of this work has focused on plants (e.g.,

22 Baker 1965; Rejmánek and Richardson 1996; Daehler 2003; Pyšek and Richardson 2007;

23 van Kleunen et al. 2010) and has identified reproductive potential, size, latitude of origin 
1 and a variety of other factors to be associated with invasion success. Complementary work

2 on plants also illustrated that there is a taxonomic and phylogenetic pattern among the

3 most successful global invaders; some plant families include disproportionally greater or

4 lower numbers of invasive species than others (Daehler 1998; Pyšek 1998; Diez et al.

5 2008), and these differences may be linked to traits typical of individual families related to

6 establishment, reproduction or dispersal (Pyšek 1998). Introduction pathways, in

7 particular international trade in horticultural plants as the most important one for plants

8 (e.g., Reichard and White 2001), also create variation in propagule pressure that differs

9 among higher taxa based on human preferences (Lambdon et al. 2008; Pyšek et al. 2011).

11 Much less is known, however, about traits promoting invasion success in insects.

12 Lawton et al. (1986) compared the frequency of insect invasions in Great Britain and

13 observed that insect orders (e.g., Hemiptera) comprised of mostly small insects were

14 disproportionately over-represented among non-native species compared to orders that

15 tend to have larger insects (e.g., Lepidoptera and Coleoptera). They concluded that this

16 pattern was consistent with theoretical predictions (Leigh 1981) of greater invasion

17 success for species with greater intrinsic rates of population growth, $r$, and greater carrying

18 capacities, $k$ because they also inferred that smaller insects would have greater values of $r$

19 and $\mathrm{k}$. The pattern was also born out for insects invading the sub-Antarctic Marion Island

20 (Gaston et al. 2001).

23 that establishment was generally associated with adult longevity and to a lesser extent with 
1 fecundity and inversely with body size. DeBach (1965) also analyzed historical

2 introductions of biological control agents and found that host specialists were more likely

3 to establish than generalists. Simberloff (1989) theorized that insect species that reproduce

4 asexually or exhibit a haplodiploid sex determination would be less subject to adverse

5 impacts from Allee effects and inbreeding during initial colonization and therefore be more

6 likely to establish. He found some confirmatory evidence for such associations by analyzing

7 historical records for attempted introductions of biological control agents.

9 More recently several works have focused on variation in characteristics associated

10 with growth and development. For example, work on the closely related springtails has

11 suggested that egg development rates are faster in invasive than indigenous species, and

12 that survival is much lower at high temperatures than in indigenous compared with

13 invasive species (Janion et al. 2010). A recent analysis of 100 pairs of non-invasive and

14 invasive non-native insect species demonstrated that the invasive species have

15 significantly higher thermal developmental thresholds than the non-invasive ones but tend

16 to develop faster (Jarošík et al. 2015). By contrast, non-native species may have lower

17 thermal requirements for completion of development.

These effects of life history traits on invasion success may explain, in part, why some

20 insect orders are more or less frequently represented in non-native assemblages. However

21 the exceptional diversity of certain orders in non-native assemblages may also result from

22 their association with known invasion pathways and consequently elevated propagule

23 pressure (Simberloff 1986). 
A good example is provided by the Hemiptera. This order is consistently over-

3 represented in non-native assemblages (Figs. 1b, 2, 3). This may be due, in part, because

4 many Hemiptera exhibit asexual reproduction. Mate-finding failure is well known to cause

5 a strong Allee effect that can greatly limit establishment in sexually reproducing insects

6 (Liebhold and Tobin 2008). Indeed, it has long been maintained that parthenogenesis is an

7 important characteristic of species invading the Southern Ocean Islands (Frenot et al.

8 2005). A further explanation for the over-representation of Hemiptera in non-native

9 assemblages is related to their association with invasion pathways, specifically their ease of

10 transport on imported plants. Liebhold et al. (2012) reported that the Hemiptera

11 accounted for about $60 \%$ of all insect specimens intercepted by border inspectors on plants

12 imported to the USA during the period 2003-2010, and that plant imports were the

13 pathway by which over $90 \%$ of established damaging non-native sap-feeding insect species

14 were initially transported to the USA. Similar characterizations of the plant import pathway

15 exist for other world regions (Kiritani and Yamamura 2003; Kenis et al. 2007; Smith et al.

16 2007; Roques et al. 2009) indicating the dominance of this pathway worldwide.

17 Thysanoptera are also commonly associated with imported plants and a large fraction of

18 species are parthenogenetic; both factors may explain their over-representation in the

19 alien assemblages (Figs. 2 \& 3).

The consistent over-representation of Psocoptera (Figs. 1b \& 2) is perhaps more of a

22 mystery. Most port inspection data do not indicate that this group is commonly associated

23 with imported commodities (McCullough et al. 2006; Kenis et al. 2007) though one study of 
1 insects intercepted at ports entering Puerto Rico (Jenkins et al. 2014) indicated that the

2 fraction of Psocoptera among all interceptions was greater than would be expected from

3 the proportion of Psocoptera among all world insect species. Psocoptera are small insects

4 feeding on fungi and algae and are believed to primarily be transported to new world

5 regions on stored food products (Schneider 2010). A large fraction of psocids is also known

6 to be parthenogenetic (Mockford 1971) and, as for the Hemiptera, this may also contribute

7 to their success as invaders.

9 The Dictyoptera and Siphonaptera were also generally over-represented in the non-

10 native assemblages. It is easy to imagine that this is a result of their close association with

11 human civilization, which would facilitate their inter-continental transport. Within the

12 Dictyoptera, the termites (Isoptera) and cockroaches (Blattodea) are often associated with

13 human-made objects, can be easily transported and find suitable resources facilitating

14 establishment. Cockroaches are particularly noteworthy invaders, and there are reports of

15 these species accompanying early human colonists (Peck and Roth 1992). Evans (2012)

16 noted that virtually all termite species that are successful invaders share three

17 characteristics: utilization of wood for food, nesting in wood, and a high capacity to

18 generate secondary reproductives. These characteristics combine to increase probability of

19 transportation of viable propagules in wood subsequently transported by humans. High

20 propagule pressure most likely also explains the dominance of Siphonaptera in alien

21 assemblages. Being parasites of both humans and livestock, they most likely have been

22 moved around the world for centuries. Sadler (1990) presented evidence that 
1 Siphonaptera were transported through the North Atlantic region by Norse warriors as

2 early as the medieval period.

3

The Diptera, Odonata, Ephemeroptera, Plecoptera and Mecoptera are consistently

5 under-represented in non-native assemblages (Fig. 3). The pathways of introduction of

6 alien dipteran species are probably more diverse than for other taxa , combining

7 hitchhiking in mosquitos, trade of horticultural plants and imported vegetable and fruit

8 crops, stored products and animal husbandry, but also a few intentional introductions for

9 biological control (Skuhravá et al. 2010). There may be many reasons for the under-

10 representation of the four other orders but the fact that most are exclusively aquatic in

11 their habitats suggests that their paucity in non-native assemblages is due to a lack of

12 pathways, more than a lack of suitable habitats. Karatayev et al. (2009) noted the general

13 rarity of invasions by aquatic insects and proposed several hypotheses to explain this

14 phenomenon. A dominant reason may be the lack of pathways that facilitate transport of

15 these species, though ballast water has been identified as a pathway for a marine splash

16 midge (Failla et al. 2015). Furthermore, most aquatic species in these groups exist for very

17 brief periods as free-living adults, also decreasing their chances for movement and

18 establishment (Karatayev et al. 2009).

20 Patterns of species diversity among orders reported here are generally similar to

21 those reported in studies of non-native insect assemblages from individual regions (Sailer

22 1978; Kiritani and Yamamura 2003; Kenis et al. 2007; Roques 2009; Yamanaka et al. 2015).

23 The current study, however, provides a novel global overview of variation in these 
1 patterns. A unique observation made here is that for all world regions the distribution

2 among insect orders of non-native assemblages is consistently different from that of native

3 assemblages (Fig. 1a).

5 Furthermore, these differences in the taxonomic composition between native and

6 non-native assemblages are completely distinct from those that differentiate island from

7 mainland assemblages (Fig. 1a). The NMDS1 axis clearly differentiates native from non-

8 native assemblages but this same axis is not associated with insularity; island assemblages

9 of both native and non-native insects are distributed across the range of NMDS1 values.

10 Thus, the characteristics of insect taxa that enable them to establish as non-native species

11 are completely different from the characteristics that make particular groups successful

12 colonizers of islands, a hypothesis that was previously suggested (Leston 1957), but

13 refuted by Simberloff (1986). Superficially, there are reasons to believe that invasions and

14 colonization of islands represent similar processes and therefore certain life history traits

15 might promote both. However, historical colonization of islands has largely occurred via

16 natural dispersal, while invasion is facilitated via pathways resulting from human activity,

17 which differ both in form and in rate from the background natural processes (Gaston et al.

18 2003; Hulme et al. 2008). The fact that these two processes generate assemblages with

19 such vastly different taxonomic composition suggests that variation in association with

20 invasion pathways plays a dominant role in selecting invading assemblages, emphasizing

21 the importance of pathway management (Hulme 2009; Lee and Chown 2009). It also

22 demonstrates that biological invasions are not a simple subset of a long-standing ecological

23 process. 
In practice, it is difficult to completely differentiate the effects of pathway

3 associations from the effects of natural history traits affecting establishment success as

4 causes of variation among taxa in their relative representation in non-native vs. native

5 assemblages. For example, the Hemiptera are known to be strongly associated with plant

6 imports, a pathway of known importance (Kiritani and Yamamura 2002, Liebhold et al.

7 2012), but their parthogenetic reproductive systems may also contribute to establishment

8 and consequently explain their dominance in non-native assemblages. However, there are

9 contravening examples where sexual invaders appear to displace ecologically similar,

10 asexual congeners (Garnas et al. 2015, this issue). It is possible that additional studies

11 might provide further insight into this problem. In the case of insect invasions, comparison

12 of native vs. non-native assemblages at the family level may provide useful information

13 identifying the primary drivers of invasions.

A surprising result from our analysis was the presence of a distinct effect of latitude

16 on the taxonomic composition of both native and non-native assemblages (Fig. 1c).

17 Latitudinal gradients in diversity are well known in insects but these gradients may vary

18 among different groups of insects (Kouki et al. 1994, Price et al. 1998, Boyero 2002). This

19 variation among taxa in latitudinal variation in diversity may be the root cause of our

20 observed association between assemblage composition and latitude (Fig. 1c).

22 The analyses reported here are based on global lists of native and non-native

23 species in various regions, but these lists may be incomplete for a variety of reasons. Some 
1 regions have been intensely sampled and their native faunas consequently well described

2 (e.g., Great Britain) although even these lists may include a few gaps. For example, we had

3 to remove the order Phthiraptera from our analysis because the data we obtained from

4 Fauna Europaea (de Jong et al. 2014) are noticeably incomplete for some European

5 countries (e.g., France and Great Britain for which no native lice are mentioned at all).

6 Other regions have received less attention and there may be proportionately more

7 undescribed species (e.g., New Zealand). Furthermore, there may be variation among world

8 regions in the intensity with which non-native species are surveyed and reported.

\section{Acknowledgements}

13

14 The reviewers are thanked for their helpful comments. PP was supported by long-term

15 research development project RVO 67985939 (The Czech Academy of Sciences) and by a

16 Praemium Academiae award from The Czech Academy of Sciences. SLC was supported by

17 Australian Antarctic Science Program Project 4307. EGB was supported by MBIE core

18 funding to Scion and the Better Border Biosecurity collaboration (www.b3nz.org).

19

20 


\section{References}

3 Arnett RH (2000) American insects: a handbook of the insects of America north of Mexico. CRC Press, Boca Raton

5 Baker HG (1965) Characteristics and modes of origin of weeds. In: Baker HG, Stebbins GL (eds) The genetics of colonizing species. Academic, New York, pp 147-69

7 Bisby, FA (2000) The quiet revolution: biodiversity informatics and the internet. Science, 289:2309-2312

9 Blackburn TM, Essl F, Evans T et al (2014) A unified classification of alien species based on 10 the magnitude of their environmental impacts. PLoS Biology 12:e1001850

11 Blackburn TM, Pyšek P, Bacher S et al (2011) A proposed unified framework for biological 12 invasions. Trends Ecol Evol 26:333-339

13 Boyero L (2002) Insect biodiversity in freshwater ecosystems: is there any latitudinal gradient? Mar Freshwater Res 53:753-755

15 Brockerhoff EG, Bain J, Kimberley M, Knížek M (2006) Interception frequency of exotic bark and ambrosia beetles (Coleoptera: Scolytinae) and relationship with establishment in New Zealand and worldwide. Can J For Res 36:289-298

18 Brockerhoff EG, Kimberley M, Liebhold AM, Haack RA, Cavey JF (2014) Predicting how altering propagule pressure changes establishment rates of biological invaders across species pools. Ecology 95:594-601

21 Carlquist S (1965) Island life. A natural history of the islands of the world. American Museum of Natural History, New York 
1 Causton CE, Peck SB, Sinclair BJ, Roque-Albelo L, Hodgson CJ, Landry B (2006) Alien insects: threats and implications for conservation of Galápagos Islands. Ann Entomol Soc Am 99:121-143

4 Cheng L (1976) Marine insects. North Holland Publishing, Amsterdam

5 Chown SL, Convey P (2016) Antarctic Entomology. Annu Rev Entomol, in press

6 Chown SL, Gremmen NJM, Gaston KJ (1998) Ecological biogeography of southern ocean islands: species-area relationships, human impacts, and conservation. Am Nat $152: 562-575$

9 Chown SL, Huiskes AHL, Gremmen NJM et al (2012) Continent-wide risk assessment for the establishment of nonindigenous species in Antarctica. Proc Natnl Acad Sci USA 109:4938-4943

Chown SL, Slabber S, McGeoch MA, Janion C, Leinaas HP (2007) Phenotypic plasticity mediates climate change responses among invasive and indigenous arthropods. Proc R Soc Lond B 274:2661-2667

15 Crawley MJ, Kornberg H, Lawton JH, Usher MB, Southwood R, O'Connor RJ, Gibbs A (1986) The population biology of invaders [and discussion]. Phil Trans R Soc B 314:711731

Daehler CC (1998) The taxonomic distribution of invasive angiosperm plants: ecological insights and comparison to agricultural weeds. Biol Conserv 84:167-180 plants: implications for conservation and restoration. Annu Rev Ecol Evol Syst 
1 DeBach P (1965) Some biological and ecological phenomena associated with colonizing entomophagous insects. In: Baker HG, Stebbins GL (eds) The genetics of colonizing species. Academic, New York, pp 287-303

4 de Jong Y et al (2014) Fauna Europaea - all European animal species on the web.

$5 \quad$ Biodiversity Data Journal 2:e4034

Diez JM, Sullivan JJ, Hulme PE, Edwards G, \& Duncan RP (2008) Darwin's naturalization conundrum: dissecting taxonomic patterns of species invasions. Ecol Lett 11:674681.

9 Elton CS (1958) The ecology of invasions by animals and plants. University of Chicago Press

10 Evans TA (2012) Invasive termites. In: Bignell DE, Roisin Y, Lo N (eds) Biology of termites: a modern synthesis. Springer Netherlands, pp 519-562

12 Failla AJ, Vasquez AA, Fujimoto M, Ram JL (2015) The ecological, economic and public health impacts of nuisance chironomids and their potential as aquatic invaders.

15 Frenot Y, Chown SL, Whinam J, Selkirk PM, Convey P, Skotnicki M, Bergstrom DM (2005) Biological invasions in the Antarctic: extent, impacts and implications. Biol Rev

18 Garnas J, Auger-Rozenberg MA, Roques A, Bertelsmeier C, Wingfield M, Saccaggi DL, Roy H, Slippers B. (2015) Complex patterns of global spread in invasive insects: Ecoevolutionary and management consequences. Biol Invas (in review)

21 Gaston KJ, Chown SL, Mercer RD (2001) The animal species-body size distribution of Marion Island. Proc Natl Acad Sci USA 98:14493-14496 
1 Gaston KJ, Jones AG, Hänel C, Chown SL (2003) Rates of species introduction to a remote oceanic island. Proc R Soc Lond B 270:1091-1098

3 Gordon DP (2010) New Zealand inventory of biodiversity, Vol. 2. Kingdom Animalia:

4 Chaetognatha, Ecdysozoa, lchnofossiIs. University of Canterbury Press,

$5 \quad$ Christchurch, New Zealand

6 Hazell SP, Vel T, Fellowes MD (2008) The role of exotic plants in the invasion of Seychelles

7 by the polyphagous insect Aleurodicus dispersus: a phylogenetically controlled

$8 \quad$ analysis. Biol Invas 10:169-175

9 Herms DA, McCullough DG (2014) Emerald ash borer invasion of North America: history,

10 biology, ecology, impacts and management. Annu Rev Entomol 59:13-30

11 Hulme PE (2009) Trade, transport and trouble: managing invasive species pathways in an 12 era of globalization. J Appl Ecol 46:10-18

13 Hulme PE, Bacher S, Kenis M et al (2008) Grasping at the routes of biological invasions: a

14 framework for integrating pathways into policy. J Appl Ecol 45:403-414

15 Janion C, Leinaas HP, Terblanche JS, Chown SL (2010) Trait means and reaction norms: the 16 consequences of climate change/invasion interactions at the organism level. Evol

$17 \quad$ Ecol 24:1365-1380

18 Jarošík V, Kenis M, Honěk A, Skuhrovec J, Pyšek P (2015) Invasive insects differ from non-

19 invasive in their thermal requirements. PLoS One 10:e0131072

20 Jenkins D.A, Mizell III RF, Van Bloem S, Whitmire S, Wiscovitch L, Zaleski C, Goenaga, R

21 (2014) An Analysis of Arthropod Interceptions by APHIS-PPQ and Customs and

22 Border Protection in Puerto Rico. Amer Entomol 60:44-55 
1 Karatayev AY, Burlakova LE, Padilla DK, Mastitsky SE, Olenin S (2009) Invaders are not a random selection of species. Biol Invas 11:2009-2019

3 Kenis M, Auger-Rozenberg M-A, Roques A, Timms L, Péré C, Cock MJW, Settele J, Augustin S, Lopez-Vaamonde C (2009) Ecological effects of invasive alien insects. Biol Invas $11: 1-45$

Kenis M, Rabitsch W, Auger-Rozenberg M-A, Roques A (2007) How can alien species inventories and interception data help us prevent insect invasions? Bull Entomol Res 97:489-502

9 Kenkel NC, Orlóci L (1986) Applying metric and nonmetric multidimensional scaling to ecological studies: some new results. Ecology 67:919-928

11 Kettunen M, Genovesi P, Gollasch S, Pagad S, Starfinger U, ten Brink P, Shine C (2009) Technical support to EU strategy on invasive alien species (IAS): assessment of the impacts of IAS in Europe and the EU (final module report for the European Commission). Institute for European Environmental Policy, Brussels

Kiritani K, Yamamura K (2003) Exotic insects and their pathways for invasion. In: Ruiz GM, Carlton JT (eds) Invasive species - vectors and management strategies. Island Press,

$$
\text { Washington, D.C., pp 44-67 }
$$

Kolar CS, Lodge DM (2001) Progress in invasion biology: predicting invaders. Trends Ecol

19 Evol 16:199-204

20 Kouki J, Niemelä P, Viitasaari M (1994). Reversed latitudinal gradient in species richness of 21 sawflies (Hymenoptera, Symphyta). Ann Zool Fenn 31:83-88

22 Lambdon P W, Pyšek P, Basnou C et al (2008) Alien flora of Europe: species diversity, 23 temporal trends, geographical patterns and research needs. Preslia 80:101-149 
1 Lawton JH, Brown KC, Crawley MJ, Way MJ, Holdgate MW, May RM et al (1986) The population and community ecology of invading insects [and discussion]. Phil Trans R Soc 314:607-617

4 Lee JE, Chown SL (2009) Breaching the dispersal barrier to invasion: quantification and management. Ecol Appl 19:1944-1959

Leigh EG Jr (1981) The average lifetime of a population in a varying environment. J Theor Biol 90:213-239

Leston D (1957) Spread potential and the colonisation of islands. Syst Biol 6:41-46

9 Liebhold AM, Tobin PC (2008) Population ecology of insect invasions and their management. Annu Rev Entomol 53:387-408

11 Liebhold AM, Work TT, McCullough DG, Cavey JF (2006) Airline baggage as a pathway for 12 alien insect species invading the United States. Am Entomol 52:48-54

13 Liebhold AM, Brockerhoff EG, Garrett LJ, Parke JL, Britton KO (2012) Live plant imports:

14 the major pathway for forest insect and pathogen invasions of the U.S. Front Ecol

15 Environ 10:135-143

16 McCullough DG, Work TT, Cavey JF, Liebhold AM, Marshall D (2006) Interceptions of 17 nonindigenous plant pests at US ports of entry and border crossings over a 17-year 18 period. Biol Invas 8:611-630

19 Mockford EL (1971) Parthenogenesis in psocids (Insecta: Psocoptera). Amer Zool 11:327339

21 Peck SB, Roth LM (1992) Cockroaches of the Galápagos Islands, Ecuador, with descriptions of three new species (Insecta: Blattodea). Can J Zool 70:2202-2217 
1 Price PW, Fernandes GW, Lara ACF, Brawn J, Barrios H, et al. 1998. Global patterns in local number of insect galling species. J Biogeogr 25:581-91

3 Puth LM, Post DM (2005) Studying invasion: have we missed the boat? Ecol Lett 8:715-721

4 Pyšek P (1998) Is there a taxonomic pattern to plant invasions? Oikos 82:282-294

5 Pyšek P, Jarošík V, Hulme PE et al (2012) A global assessment of invasive plant impacts on resident species, communities and ecosystems: the interaction of impact measures, invading species' traits and environment. Global Change Biol 18:1725-1737

8 Pyšek P, Jarošík V, Pergl J (2011) Alien plants introduced by different pathways differ in invasion success: unintentional introductions as greater threat to natural areas? PLoS ONE 6:e24890

11 Pyšek P, Richardson DM (2007) Traits associated with invasiveness in alien plants: Where do we stand? In: Nentwig W (ed.), Biological invasions. Berlin \& Heidelberg,

13 Germany: Springer-Verlag, pp 97-125.

14 Reichard SH, White P (2001) Horticulture as a pathway of invasive plant introductions in the United States. BioScience 51:103-113

16 Rejmánek M, Richardson DM (1996) What attributes make some plant species more invasive? Ecology 77:1655-61

18 Ricciardi A, Hoopes MF, Marchetti MP, Lockwood JL (2013) Progress toward understanding

19 the ecological impacts of nonnative species. Ecol Monogr 83:263-282

20 Richardson DM, Pyšek P (2006) Plant invasions: merging the concepts of species

21 invasiveness and community invasibility. Progr Phys Geog 30:409-431

22 Ricklefs RE, Bermingham E (2002) The concept of the taxon cycle in biogeography. Glob

$23 \quad$ Ecol Biogeogr 11:353-361 
1 Roques A (2010) Taxonomy, time and geographic patterns. Chapter 2. In: Roques A et al. (eds) Alien terrestrial arthropods of Europe. BioRisk 4(1): 11-26

3 Roques A, Rabitsch W, Rasplus J-Y et al (2009) Alien terrestrial invertebrates of Europe. In:

4 Nentwig W, Hulme P, Pyšek P, Vilà M (eds) Handbook of alien species in Europe.

5 Dordrecht, Netherlands: Springer-Verlag, pp 63-79

6 Sadler J (1990) Beetles, boats and biogeography. Insect invaders of the North Atlantic. Acta

$7 \quad$ Archaeol 61:199-211

8 Sailer RI (1978) Our immigrant insect fauna. Bull Entomol Soc Am 24:3-11

9 Schneider N (2010) Psocids (Psocoptera). In: Roques A et al (eds) Alien terrestrial

$10 \quad$ arthropods of Europe. BioRisk 4:793-805

11 Simberloff D (1986) Introduced insects: a biogeographic and systematic perspective. In:

12 Mooney HA, Drake JA (eds) Ecology of biological invasions of North America and

13 Hawaii. New York, USA: Springer, pp 3-26

14 Simberloff D (1989) Which insect introductions succeed and which fail. In: Drake JA et al

15 (eds) Biological invasions: a global perspective. Chichester, UK: Wiley \& Sons, Ltd., $16 \quad \operatorname{pp} 61-75$

17 Simberloff D, Martin JL, Genovesi P et al (2013) Impacts of biological invasions: what's

18 what and the way forward. Trends Ecol Evol 28:58-66

19 Skuhravá M, Martinez M, Roques A (2010). Diptera. Chapter 10. Alien terrestrial

20 arthropods of Europe. BioRisk 4:553-602

21 Smith RM, Baker RHA, Malumphy CP et al (2007) Recent nonnative invertebrate plant pest

22 establishments in Great Britain: origins, pathways, and trends. Agric For Entomol

$239: 307-326$ 
1 van Kleunen M, Weber E, Fischer M (2010) A meta-analysis of trait differences between invasive and non-invasive plant species. Ecol Lett 13:235-245

3 Yamanaka T, Morimoto N, Nishida GM, Kiritani K, Moriya S, Liebhold AM (2015) 
Table 1. Sources of data on counts of insect species by order.

\begin{tabular}{|c|c|c|c|}
\hline Region & Assemblage & $\begin{array}{c}\text { Year } \\
\text { Compiled }\end{array}$ & Source \\
\hline Canary Islands & native & 2013 & de Jong et al. (2014) \\
\hline Canary Islands & non-native & 2013 & Roques (2010) \\
\hline Corsica & native & 2013 & de Jong et al. (2014) \\
\hline Corsica & non-native & 2013 & Roques (2010) \\
\hline Europe & native & 2013 & de Jong et al. (2014) \\
\hline Europe & non-native & 2013 & Roques (2010) \\
\hline France & native & 2013 & de Jong et al. (2014) \\
\hline France & non-native & 2013 & Roques (2010) \\
\hline Great Britain & native & 2013 & de Jong et al. (2014) \\
\hline Great Britain & non-native & 2013 & Roques (2010) \\
\hline Hawaiian Islands & native & 2014 & Yamanaka et al. (2015) \\
\hline Hawaiian Islands & non-native & 2014 & Yamanaka et al. (2015) \\
\hline Italy & native & 2013 & de Jong et al. (2014) \\
\hline Italy & non-native & 2013 & Roques (2010) \\
\hline Japan & native & 2014 & Yamanaka et al. (2015) \\
\hline Japan & non-native & 2014 & Yamanaka et al. (2015) \\
\hline Madeira & native & 2013 & de Jong et al. (2014) \\
\hline Madeira & non-native & 2013 & Roques (2010) \\
\hline Malta & native & 2013 & de Jong et al. (2014) \\
\hline Malta & non-native & 2013 & Roques (2010) \\
\hline North America & native & 2014 & Yamanaka et al. (2015) \\
\hline North America & non-native & 2014 & Yamanaka et al. (2015) \\
\hline New Zealand & native & 1998 & Gordon (2010) \\
\hline New Zealand & non-native & 2009 & Gordon (2010) \\
\hline Ogasawara Islands & native & 2014 & Yamanaka et al. (2015) \\
\hline Ogasawara Islands & non-native & 2014 & Yamanaka et al. (2015) \\
\hline Okinawa Islands & native & 2014 & Yamanaka et al. (2015) \\
\hline Okinawa Islands & non-native & 2014 & Yamanaka et al. (2015) \\
\hline Portugal & native & 2013 & de Jong et al. (2014) \\
\hline Portugal & non-native & 2013 & Roques (2010) \\
\hline Sardinia & native & 2013 & de Jong et al. (2014) \\
\hline Sardinia & non-native & 2013 & Roques (2010) \\
\hline Sicily & native & 2013 & de Jong et al. (2014) \\
\hline Sicily & non-native & 2013 & Roques (2010) \\
\hline Southern Islands* & native & 2013 & Chown and Convey (2016) \\
\hline Southern Islands* & non-native & 2013 & Chown and Convey (2016) \\
\hline Spain & Native & 2013 & de Jong et al. (2014) \\
\hline Spain & non-native & 2013 & Roques (2010) \\
\hline Galápagos Islands & non-native & 2005 & Causton et al. (2006) \\
\hline World & Native & 1999 & Arnett (2000) \\
\hline
\end{tabular}




\section{Figure Captions}

3 Figure 1. Non-metric Multidimensional scaling ordination (NMDS) of numbers of insects in

4 each order among native and non-native assemblages (data for Siphonaptera were

5 excluded. See Figs. S1 and S2 for comparable analysis that includes Siphonaptera data) (a)

6 Scatterplot of NMDS scores for each native ("N") and alien (A) assemblage. Region

7 abbreviations: Great Britain: 'Brit', Canary Islands: 'Canar', Corsica: 'Cors', Europe: 'Eur',

8 France: 'Fran', Hawaiian Islands: 'Hawa', Italy: 'Ital', Japan: 'Jap', Madeira: 'Mad', Malta:

9 'Malt', North America: 'N.Amer', New Zealand: 'NZ' Ogas-N', Ogasawara Islands: 'Ogas-A',

10 Okinawa Islands: 'Okin', Portugal: 'Port', Sardinia: 'Sard', Sicily: 'Sic', Southern Oceanic

11 Islands: 'S.Isl', Spain: 'Spain', Galápagos Islands: 'Galap', World: 'world'. Green dots

12 correspond to islands and red dots are mainland regions. (b) Scatterplot of NMDS loadings

13 for each insect order. Insect orders are abbreviated by the first 3 characters of their name.

14 (c) Contour of latitude across NMDS space.

16 Figure 2. Scatterplots of numbers of native vs. non-native species in each of 19 world

17 regions. Solid line corresponds to the number of non-native species expected under the

18 assumption that the fraction of all non-native species in a given order is the same as the

19 fraction among all native species in that same order. Shaded area represents 95\%

20 prediction interval under the assumption that the ratio of non-native to native species in

21 each order is the same as for all insect species. 
1 Figure 3. Box and whisker plots for each insect order of the distribution of deviations from

2 expected numbers of species of alien species under the assumption that the fraction of all

3 non-native species in a given order is the same as the fraction among all native species in

4 that same order. 


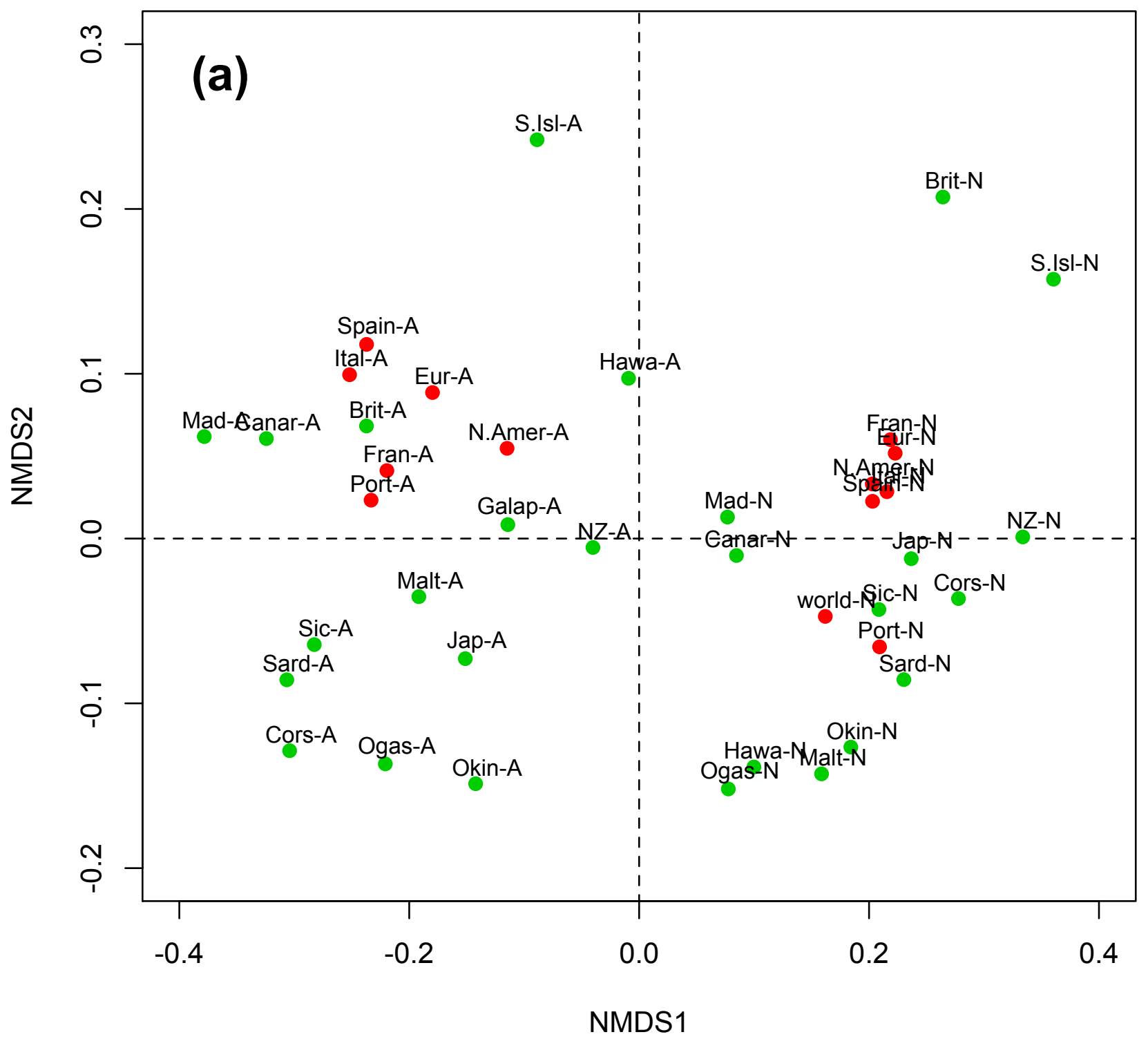

4 


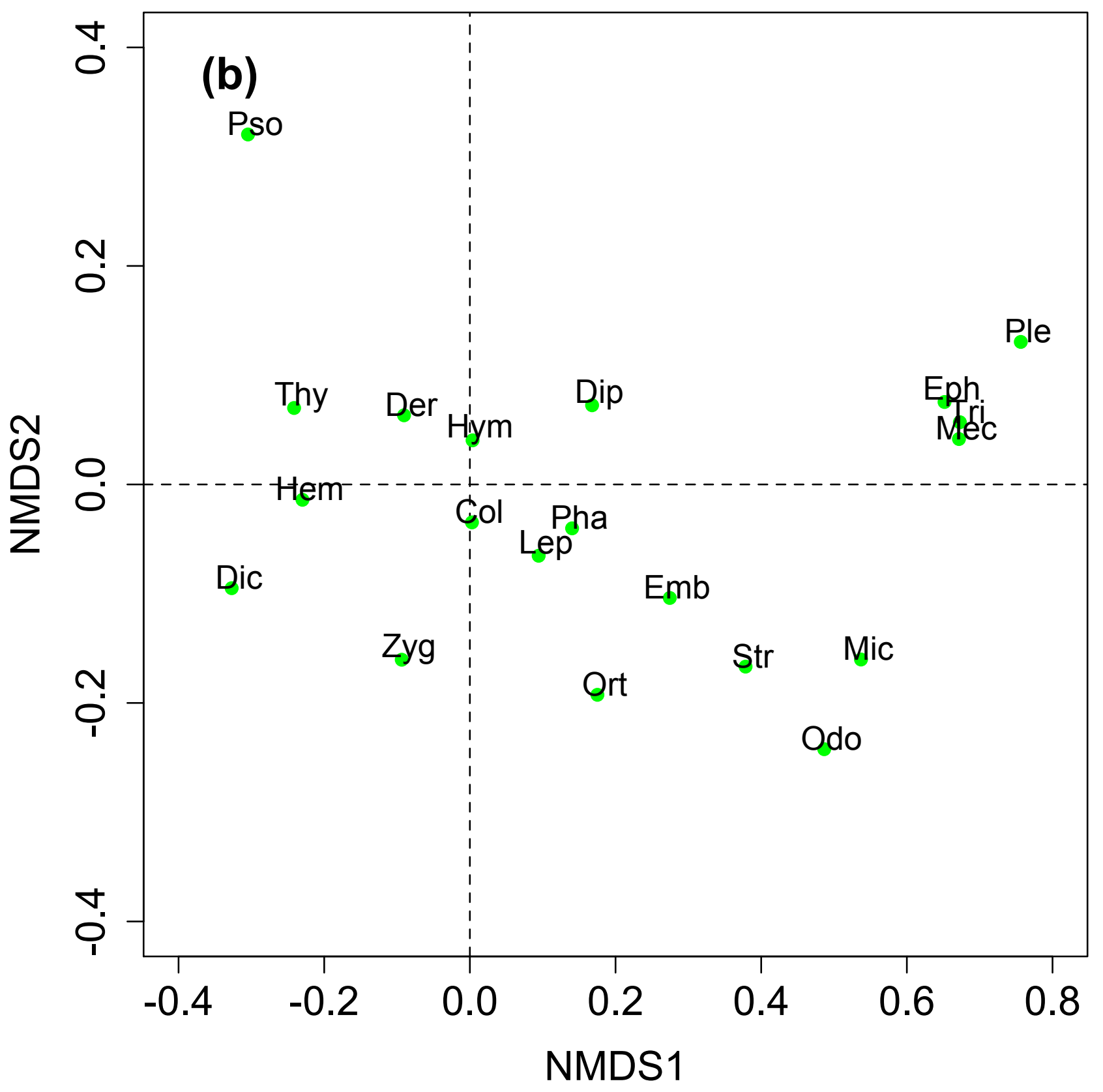




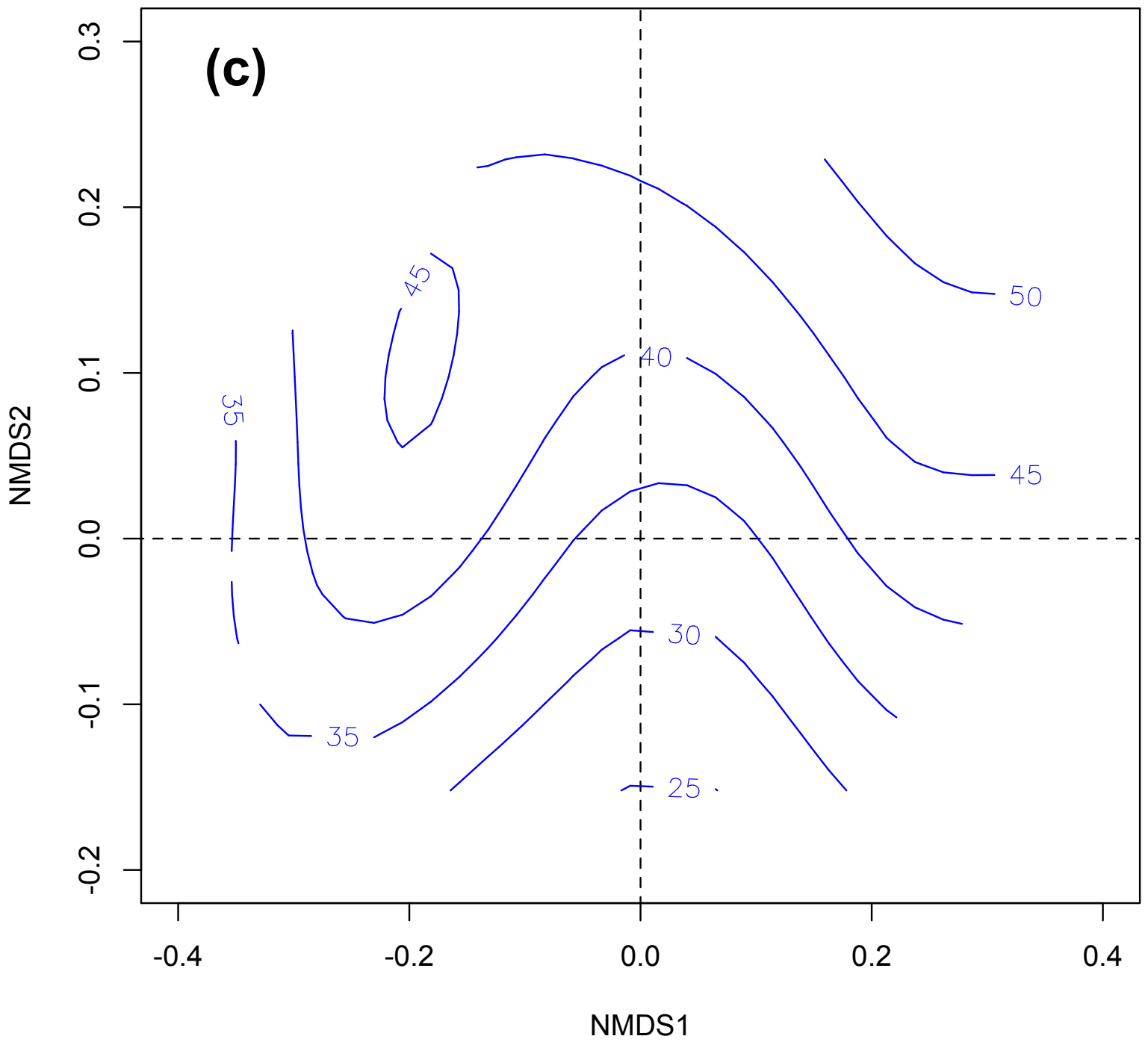

3

4

Figure 1c 

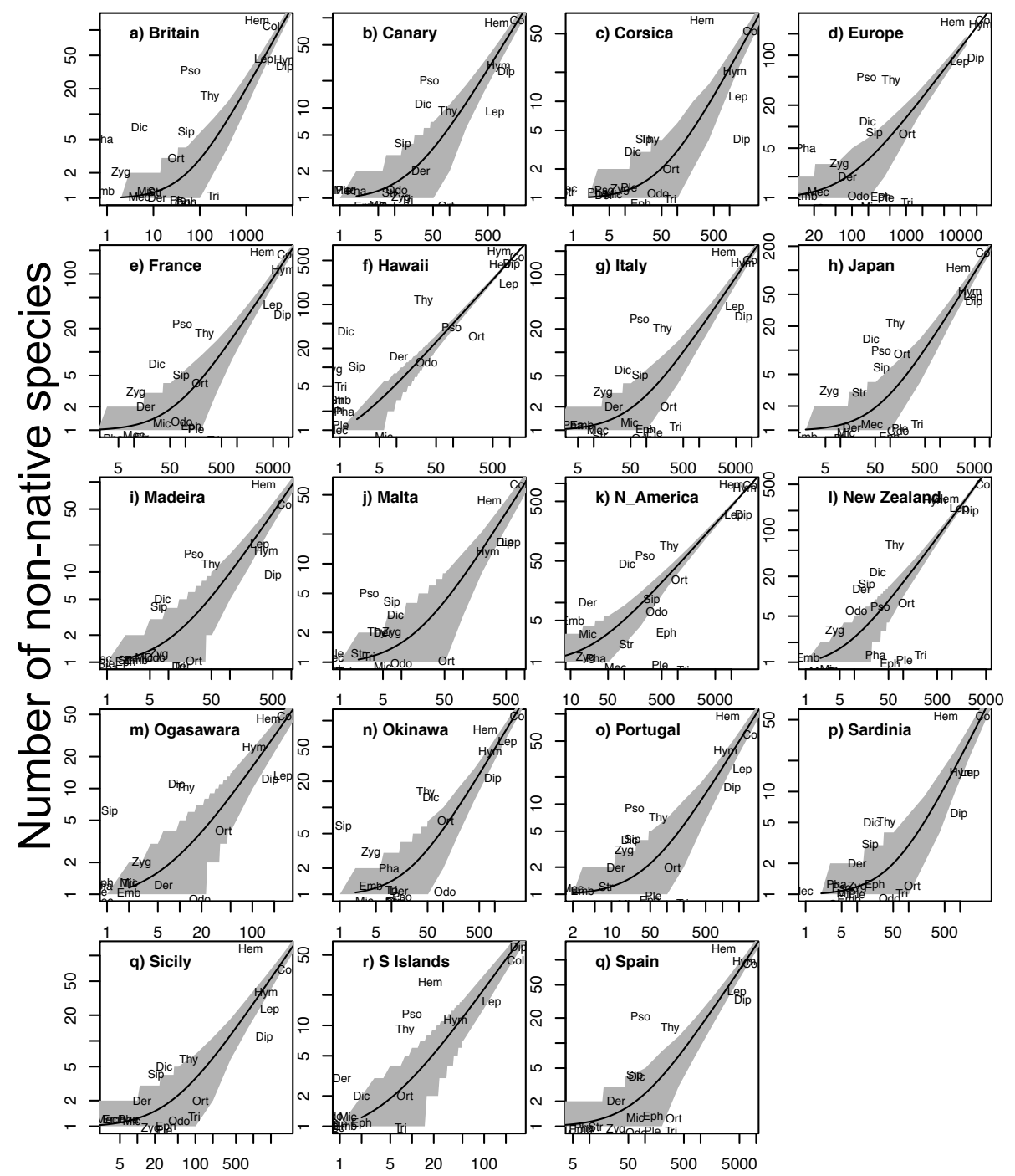

\section{Number of native species}



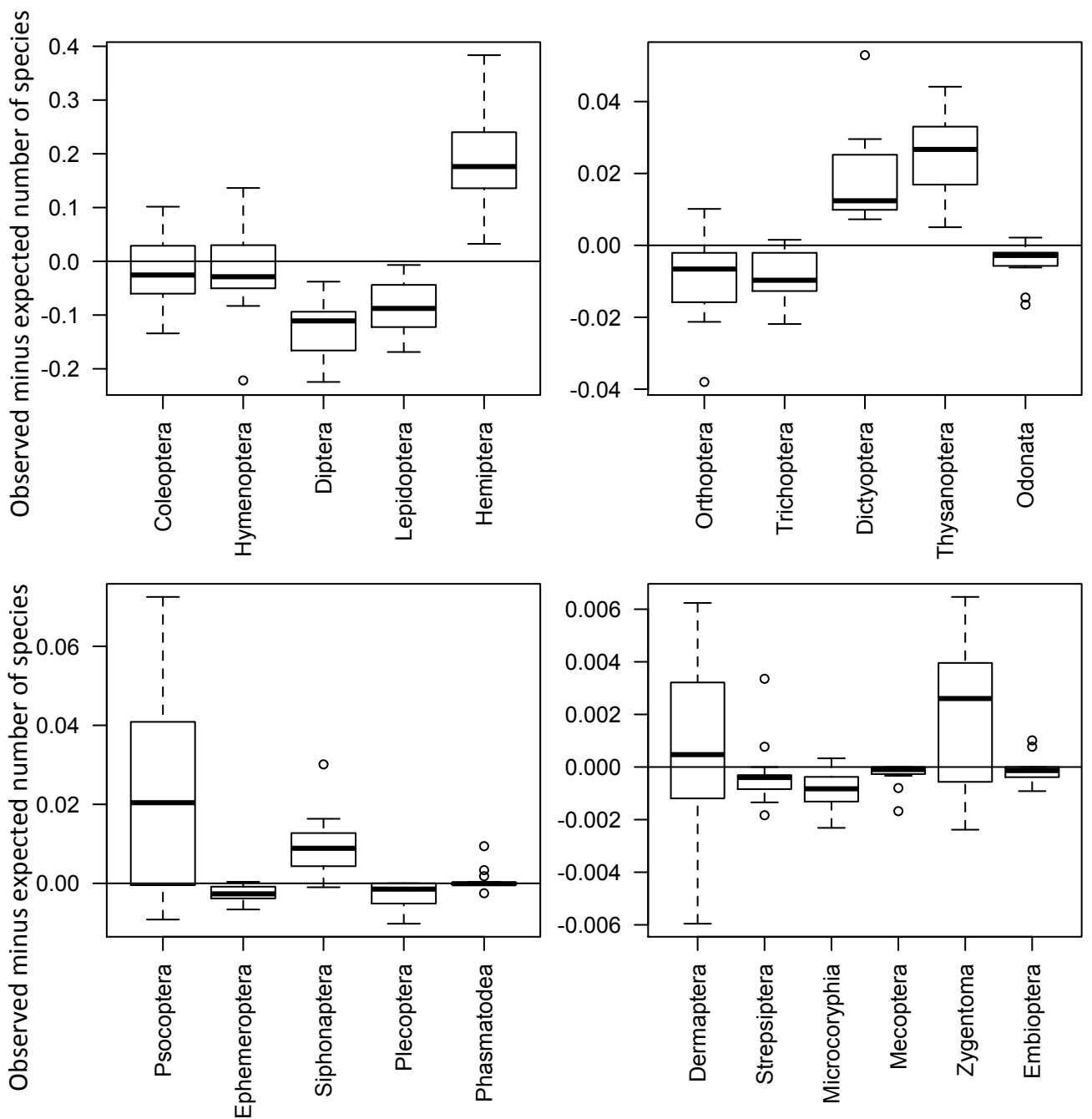